Short Report

\title{
Shrinking areas and mortality: An artefact of deprivation effects in the West of Scotland?
}

\author{
Daniel J. Exeter ${ }^{\mathrm{a}, *}$, Paul J. Boyle ${ }^{\mathrm{b}, \mathrm{c}}$, Zhiqiang Feng $^{\mathrm{b}}$, Mark Boyle ${ }^{\mathrm{d}}$ \\ ${ }^{a}$ Section of Epidemiology and Biostatistics, School of Population Health, University of Auckland, P.O. Box 92019, Auckland, New Zealand \\ b School of Geography and Geosciences, University of St. Andrews, St. Andrews, UK \\ c Social Dimensions of Health Institute, Universities of Dundee and St. Andrews, Dundee, UK \\ ${ }^{\mathrm{d}}$ Department of Geography and Sociology, University of Strathclyde, Glasgow, UK
}

\section{A R T I C L E I N F O}

\section{Article history:}

Received 29 August 2007

Received in revised form

7 February 2008

Accepted 1 April 2008

\section{Keywords:}

Population change

Mortality

Deprivation

West of Scotland

Health Boards

\begin{abstract}
A B S T R A C T
A number of studies have shown that mortality rates are highest in areas that are experiencing population decline. A recent study suggests that this relationship disappears when area deprivation is accounted for. We extend this research to consider the relationship between population change and mortality in five Health Boards in the West of Scotland-a region with some of the worst mortality rates in Europe. For the area as a whole and all five Health Boards separately, we find a significant negative association between population change and mortality, but in each case this relationship disappears when small area deprivation is accounted for. This confirms our previous conclusion that it is more important to account for deprivation than population decline in health resource allocation.
\end{abstract}

(c) 2008 Elsevier Ltd. All rights reserved.

\section{Introduction}

A number of studies have considered the ecological relationship between mortality and population change. Early studies found that places experiencing population growth during the rapid urbanisation of the 18th century tended to have higher mortality (Farr, 1875; Lewis-Faning, 1930) while more recent studies demonstrate a reversal of this relationship, such that declining areas tend to have higher mortality rates (Davey Smith et al., 1998, 2001; Molarius and Janson, 2000; Regidor et al., 2002). It has been suggested that this relationship should be taken into account when allocating health-related financial resources as declining areas have experienced relative budgetary declines which do not reflect the higher mortality experienced there (Davey Smith et al., 1998, p. 1440). However, while recent Scottish studies which analysed mortality data for small areas throughout the whole of Scotland also found a negative relationship between population change and mortality, this disappeared once deprivation circumstances were accounted for (Boyle et al., 2004; Exeter et al., 2005a).

\footnotetext{
Abbreviations: GROS: General Register Office for Scotland, CATT: Consistent Areas Through Time.

* Corresponding author. Tel.: +6493737599.

E-mail address: d.exeter@auckland.ac.nz (D.J. Exeter).
}

This study extends our previous Scottish analysis (Exeter et al., 2005a) by conducting five separate analyses for each of the Health Boards in the West of Scotland. These Health Boards include some of the most deprived parts of Europe, with some of the highest mortality rates (Leyland et al., 2007). Parts of Glasgow, for example, consistently top the mortality rankings in the UK. However, the five Health Boards also include some relatively wealthy areas which have much lower mortality rates. This analysis allows us to test whether our previous results for the whole of Scotland are consistent at smaller scales of analysis (Health Boards) and when we focus on particularly deprived settings.

First, we tested whether there was a negative relationship between population change and mortality in the entire study area and each of these Health Boards separately. Second, we examined whether this relationship held once deprivation circumstances were accounted for.

\section{Data and methods}

We used mortality data for 1999-2001 obtained from the General Register Office for Scotland (GROS) with the European Standard population used as a weight to create age-standardised mortality rates. Table 1 provides the deaths and populations for each of the Health Boards, as well as the number of 'Consistent Areas Through Time' (CATTs) for which the data were aggregated 
Table 1

Descriptive statistics

\begin{tabular}{|c|c|c|c|c|c|}
\hline & Deaths & Population & Number of CATTs & Minimum CATT population & Maximum CATT population \\
\hline West of Scotland & 89,228 & $2,487,697$ & 4974 & 50 & 18,299 \\
\hline Ayrshire and Arran & 13,807 & 368,851 & 815 & 50 & 11,274 \\
\hline Argyll and Clyde & 15,736 & 424,110 & 826 & 52 & 12,620 \\
\hline Forth Valley & 9113 & 279,776 & 448 & 53 & 11,282 \\
\hline Greater Glasgow & 32,654 & 862,873 & 1863 & 50 & 8341 \\
\hline Lanarkshire & 17,918 & 552,087 & 1022 & 54 & 18,299 \\
\hline
\end{tabular}

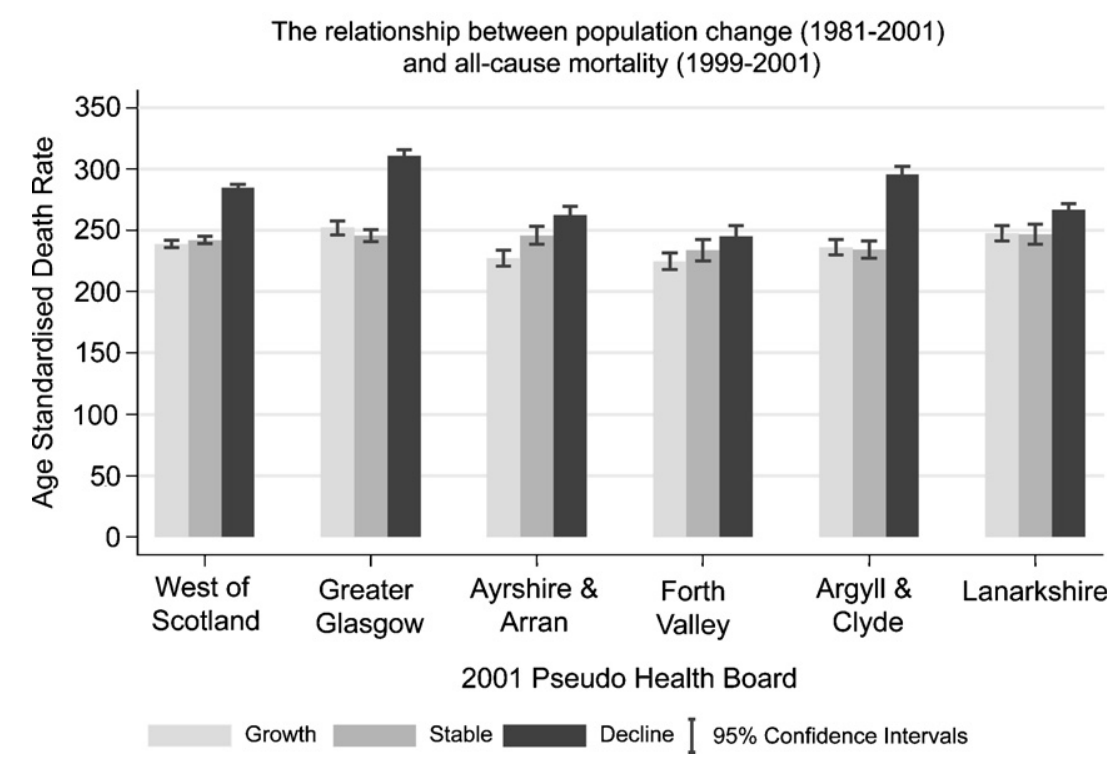

Fig. 1. The relationship between population change (1981-2001) and all-cause mortality (1999-2001).

(Exeter et al., 2005b). ${ }^{1}$ The minimum population in a single CATT was 50 and the maximum was 18,299 . Census data can be reliably aggregated for the CATTs from the 1981, 1991 and 2001 censuses and we calculated population change between 1981 and 2001; there is evidence that the population denominators from the 1981 and 2001 censuses are more reliable than for 1991 (Simpson and Dorling, 1994). We also calculated Carstairs deprivation scores (Carstairs and Morris, 1991) for the CATTs, using 2001 census data.

The CATTs were then aggregated into population-weighted quintiles, based on the Carstairs deprivation score, for the West of Scotland as a whole and for each Health Board separately. Within each quintile, three categories of CATT were distinguished, based on the population change between 1981 and 2001: 'declining areas' experiencing at least 10\% population decline between 1981 and 2001; 'growing areas' experiencing at least 10\% population increase between 1981 and 2001; and 'stable areas', which fell in between. Finally, we calculated all-cause mortality rates using the direct method for these various categories.

\section{Results and discussion}

Similar to most recent studies, we find a negative relationship between population change and mortality for the West of Scotland as a whole and for each Health Board separately (Fig. 1). The differences between the declining and growing areas were significant in each case. Most notably, the rates were much higher in the areas experiencing decline over the 20 -year period.

\footnotetext{
${ }^{1}$ There are 10,058 CATTs in Scotland.
}

However, the population gradient effectively disappears when we divide the West of Scotland and each Health Board into deprivation quintiles and in nearly all cases, and the mortality rates for the declining areas were not significantly different to the mortality rates for the growing areas (Fig. 2a-f). The finding is highly consistent even though the deprivation circumstances and mortality rates vary across the five Health Boards. Fig. 2a-f also shows that in a few cases where there were significant differences between the mortality rates in growing and declining areas, the mortality rates were actually higher in the areas of population growth.

These results suggest that the negative relationship between population change and mortality in the West of Scotland and its five constituent Health Boards is an artefact of the relationship between area deprivation and mortality. Declining areas tend to be more deprived. This confirms our previous conclusion (Exeter et al., 2005a) that while resource allocation clearly needs to include the population base as a key element of the calculation, it is not necessary to allocate additional resources to those areas experiencing population decline. Instead, the formula used to distribute health resources should continue to be related to deprivation circumstances, which is correlated with population decline. This reflects the current strategy in Scotland. Since 2000, approximately $70 \%$ of the health resource expenditure at the NHS Health Board level in Scotland has been apportioned according to the 'Arbuthnott' formula, which comprises four measures of health, including the population distribution living in a health board, the age/gender mix of the population, level of deprivation, and adjustments for the level of rural and remote areas within a health board (The Scottish Executive, 2000). While the precise details of this formula may be debated, the focus on deprivation in 
a The relationship between population change (1981-2001), deprivation and mortality (1999-2001)

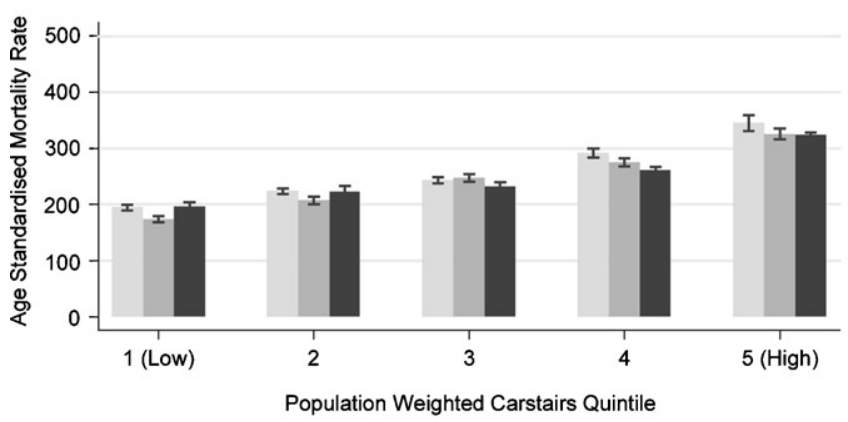

C

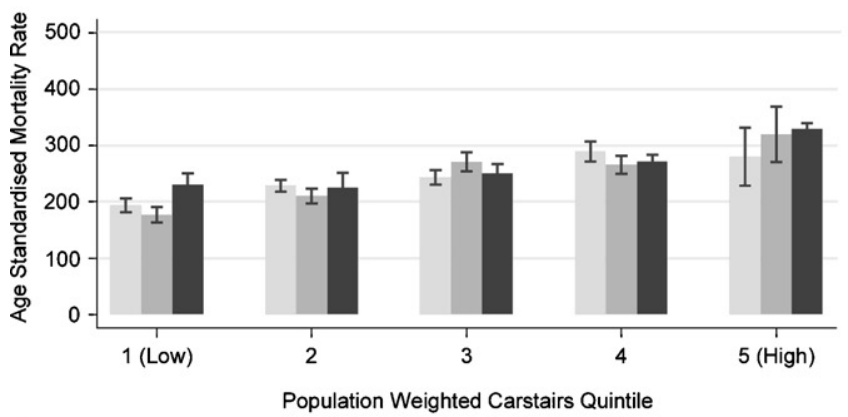

e

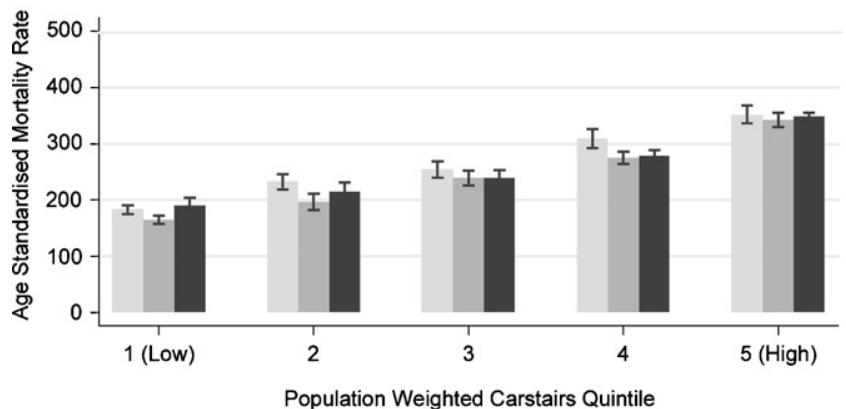

Growth

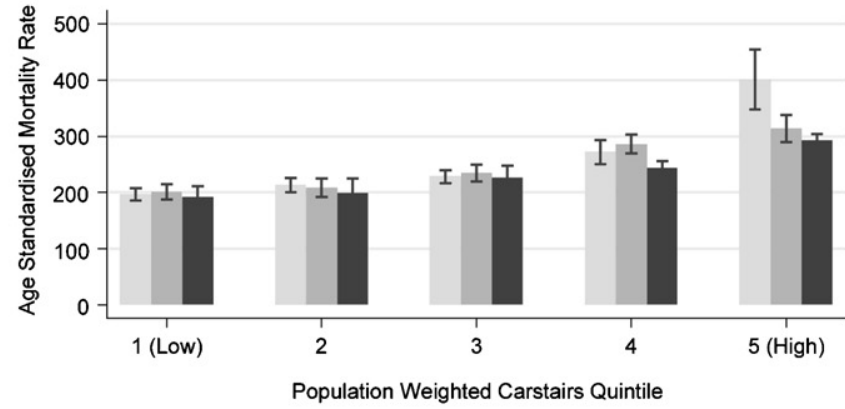

d

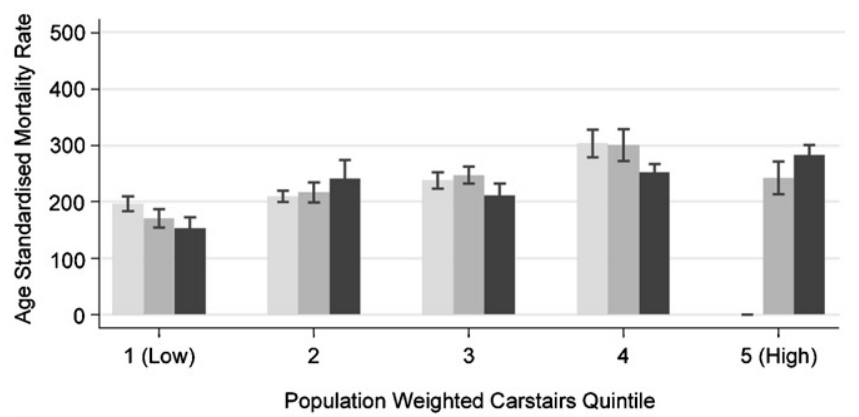

$f$

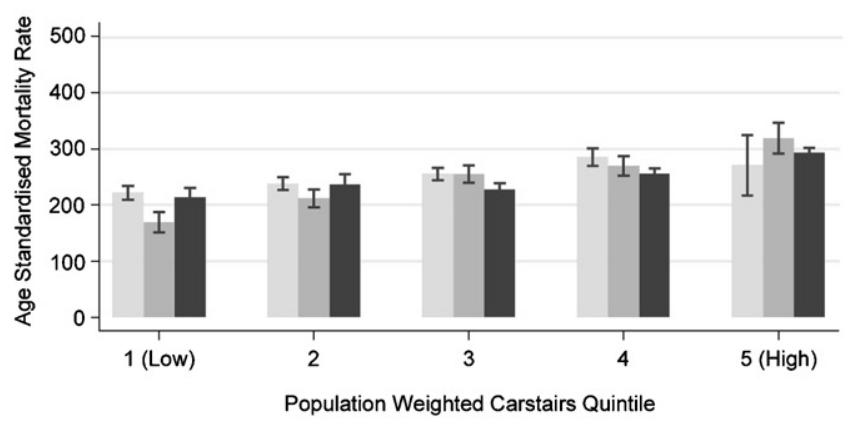

Decline I $95 \%$ Confidence Intervals

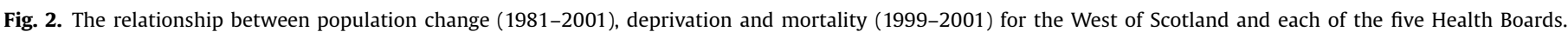

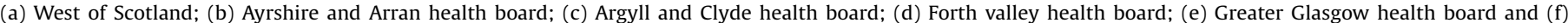
Lanarkshire health board.

addition to absolute population distribution seems sensible, although we would acknowledge that there may be unique health care circumstances in areas where population decline is occurring, particularly as unmet need is likely to be higher in these deprived places.

\section{Acknowledgements}

This research was funded by the NHS Scotland, West of Scotland Research and Development. Census output is Crown copyright and is reproduced with the permission of the Controller of HMSO and the Queen's Printer for Scotland.

\section{References}

Boyle, P., Exeter, D., Flowerdew, R., 2004. The role of population change in widening the mortality gap in Scotland. Area 36 (2), 164-173.

Carstairs, V., Morris, R., 1991. Deprivation and Health in Scotland. Aberdeen University Press.

Davey Smith, G., Shaw, M., Dorling, D., 1998. Shrinking areas and mortality. Lancet 352 (9138), 1439-1440.
Davey Smith, G., Shaw, M., Dorling, D., 2001. Population change and mortality in men and women. Journal of Epidemiology and Community Health 55 (1), 9.

Exeter, D., Boyle, P.J., Feng, Z., Flowerdew, R., Schierloh, N., 2005a. The creation of 'consistent areas through time' (CATTs) in Scotland, 1981-2001. Population Trends 119 (Spring), 28-36.

Exeter, D.J., Feng, Z., Flowerdew, R., Boyle, P.J., 2005b. Shrinking areas and mortality: an artefact of deprivation effects? Journal of Epidemiology and Community Health 59, 924-926.

Farr, W., 1875. Supplement to the 35th Annual Report of the Registrar General for the Years 1861-1870. HMSO, London.

Lewis-Faning, E., 1930. A survey of the mortality in Dr. Farr's 63 healthy districts of England and Wales during the period 1851-1925. Journal of Hygiene 30, 121-153.

Leyland, A.H., Dundas, R., McLoone, P., Boddy, F.A., 2007. Inequalities in mortality in Scotland, 1981-2001. MRC Social and Public Health Sciences Unit Occasional Paper No. 16. MRC Social and Public Health Sciences Unit, Glasgow.

Molarius, A., Janson, S., 2000. Population change and mortality in men and women. Journal of Epidemiology and Community Health 54 (10), 772.

Regidor, E., Calle, M.E., Domínguez, V., Navarro, P., 2002. Inequalities in mortality in shrinking and growing areas. Journal of Epidemiology and Community Health 56 (12), 919-921.

Simpson, S., Dorling, D., 1994. Those missing millions-implications for social statistics of nonresponse to the 1991 census. Journal of Social Policy 23 (4), 543-567.

The Scottish Executive, 2000. Fair Shares for All. The Scottish Executive, Edinburgh. 